\title{
Medical Education in the Field of Communication as a Value and a Means of Health Quality Improvement
}

\section{Jana Goriup - Kleopatra Kodričc}

Vita brevis, ars longa, accasio valucris, experientia periculosa, idicium, difficile. Nec vero satis est, medicum suum fecisse officium, nisi suum quoque aegrotus, sum astantes faciant, sintque: externarite comparata.

Life is short, art is long, opportunity is fleeting, experience is dangerous, judgement is hard. It is not enough if the doctor does his job, when it is necessary, but the patients have to contribute their part as well and so do other life circumstances. (first Hipocrates Aforism)

\begin{abstract}
The article discusses the issues of communication between a doctor and a patient as one of the main approaches within the patients' medical treatment. This approach, which includes the field of communication in medicine as a value, more and more appears as obligatory not only in the field of profession itself, but also in the field of the patients' needs. Communication covers a huge part of our social as well as intimate lives. Our social functioning is based on communication. The transfer and preserving of values is based on communication. Especially in the field of medicine, the function of communication appears to be one of the key elements to allow a better and complete treatment of the patient. The article discusses studies which have shown that communication skills have to be developed, it is advisable to introduce them into the educational programmes for med students and medical staff. Researches have shown that students, who were taught the field of communication skills, later as doctors or medical staff obtained a lot more information about patients than those who were not given such education. Key words: communication, doctor, patient, education, values.
\end{abstract}

\footnotetext{
* Jana Goriup, University of Maribor, Maribor, Slovenia; jana.goriup@um.si Kleopatra Kodrič, University of Maribor, Maribor, Slovenia; kleokodric@ gmail.com
} 


\section{Introduction}

Communication is the central and most basic process in society. Communication intertwines the broadest segment of society, i.e. from the public sphere to the most basic cell of society - the family. Apart from all the important processes taking place in our lives and the public sphere, communication (between family members, within a team, at work, between doctors and patients) and solving problems as current issues have become the central thematic chapters in the field of health. Brajša (1982) defines conflicts as a relationship crisis or crisis in development. The one who does not admit the existence of the development crisis denies development. There is no development without conflicts (Brajša, 1982, p. 52). The doctor-patient relationship and the question of trust are among the key issues that must be dealt with.

Communication allows people to interact and co-operate. Communication in the field of medicine represents a two-way flow of messages between the doctor and the nurse on one side and the patient on the other side, with empathy and trust being very important here. The essence of the doctor's empathy is his/her ability to listen. Doctors who are able to recognize their patients' feelings are more successful in their treatment.

When getting in touch with a patient, the doctor takes responsibility not only for the treatment but also for the patient as an individual. An individual approach based on mutual communication must be applied. The essence of building trust is communication, however, it must not be stereotypical, routine, phlegmatic or impersonal.

The relationship between the doctor and the patient is based on an interactive process and has to be equal. The doctor has the role of an experienced professional and the patient is his/her active co-operator in the process of treatment. While building the relationship with a patient, The Medical Deontology Codex (http://www.zdravniskazbornica.si/zzs.asp?FolderId=386) can be helpful for the doctors. The Codex is meant to be used as a guide for doctors when assessing his way of treatment. In the postmodern society, the relationship and communication between the doctor and the patient are often perceived as negative, especially due to the deficient and (sometimes) simple health care organization. Doctors do not have enough time for one patient (7 minutes on average!!!) and patients become objects for the doctor. Thus, medicine is going through a crisis of mistrust based on the depersonalisation of the patient.

\section{Communication and education of doctors}

In the process of communication with patients, doctors often face demanding situations since clinical practice requires high degree of empathy on the side of doctors. On the other hand, doctors are also advised not to show patients their feelings and emotions. They must realize that empathic communication is 
neither a method nor a technique and it cannot be "easily learnt". However, sympathy and empathy are crucial dimensions within the relationship between the doctor and the patient.

In their offices, doctors are confronted with their daily routine work because of many patients, but especially due to the enormous lack of time for them. Doctors often advise their patients (by routine) to go to another doctor, i.e. to see a specialist. The result of such a relationship is unsatisfied and disappointed patients who wander from one office to another, from clinic to clinic and whose expectations have not been fulfilled (Gottschlich, 1998, p. 35). A respect towards patients' autonomy and dignity are the essential features of doctors' empathetic communication.

Ule (2003) states that the results of research on general medicine study programmes show that doctors do not possess enough knowledge about communication. During their studies, they are only given general instructions on how to interview patients. These instructions are referred to diagnostic methods. Most doctors are enabled to competently find the history of physical symptoms, however, they are not trained nor motivated to connect these to patients' psychological and/or social symptoms (for example: fears, conflicts in their surroundings, etc.). Thus, the author notices that a lot of students finish their medicine studies without adequate communication skills.

In the paper entitled Communication Skills for Medicine (2004) the authors Margaret Lloyd and Robert Bor discuss what should good communication be like, reminding that communication is the core of health care. Special attention should be paid to the research of Peter Magguire in Manchester who, together with students of medicine, interviewed patients about the students' ability to perform an interview. The patients were attracted by those interviewers who showed warmth and attention as well as those they could easily communicate with. Those students introduced themselves to the patients, showed selfawareness, listened to the patients, reacted to their comments and asked questions in an appropriate way without repeating themselves. This is also the answer to the question why good communication is important. It allows a better care of patients.

Doctors who communicate with their patients well and in an appropriate way, set a detailed diagnosis and can also see a patient's emotional instability. Thanks to the possession of that skill, patients trust the doctor and follow the doctor's instructions during treatment. It is also evident that communication has a positive impact on patients' physical condition, e.g. their blood pressure. Research has shown that patients whose communication with their doctors was successful, had less problems with high blood pressure or were successful at stabilising it (Lloyd and Bor, 2004, pp. 3-4).

Each patient must be aware of his role and tasks in the process of diagnostics, during treatment and has to take responsibility for this process. One of the 
patient's task it to respond to the doctor's findings and initiatives, passively or actively depending on the situation.

Despite the above mentioned, there is still some bad communication present between the doctor and the patient. A research (Lloyd and Bor, 2004), focused on the patients' reactions to the surgeon's demands, has been realised in Florida. Comparing the patients' reactions to the surgeon's demands, the complaints mainly referred to the doctors' behaviour, i.e. they were not listening, did not inform the patients and did not show any interest or understanding towards them. In countries where patients complain less about their doctors they openly express their dissatisfaction regarding the way their doctors communicate with them. The authors' answer to the question whether communication skills can be learnt is that this is impossible if med students copy the communication model of their teachers. A good communication model needs effective elementary schooling and education in the field of communication. Realizing this fact, some medical educational institutions have already reacted to the need for good elementary communication and have already included a subject based exclusively on gaining knowledge and skills in the field of communication into the process of professional (medical) education.

In the 1970s of the last century, studies were performed, by students of psychiatry, too, in the field of teaching communication between doctors and patients to find out about the problems in the doctor-patient communication. The most important two reasons standing out were that the doctors did not obtain all necessary information about the patient and they "forgot" to ask the patient some essential questions about their problems, since they did not notice any nonverbal messages of the patient: in brief, they showed no interest (Lloyd and Bor, 2004, pp. 4-5).

In the course of this study, the students were divided into two groups, the control group and the feedback group. Their task was to obtain information about the patient and his/her anamnesis within 15 minutes while being recorded. An additional task of the feedback group was to handle two more patients. Again, this procedure was recorded. After the interviews, they discussed their mistakes with their mentor. Afterwards, both groups made an additional interview with the patients, which showed that the feedback group was more successful in communication, since they had obtained three times more information about the family anamnesis of the patients than the control group. Similar studies were realized with the medical staff, too, and most of them showed that students, who had been taught the field of communication with the patient, in the end had much more success in communication with patients. An interesting question, which arose in this, was whether the gained knowledge in the field of communication would fade after some time or it would remain. The question was answered and confirmed by the same study four to six years later, when the interviewed people, who had been the same students at that time, were already doctors. Again, the hypothesis confirmed that the feedback group students, i.e. 
the group which had attended additional education in the field of communication with patients, were better at communication. Finally, we can confirm the fact that good communication can be learnt and it helps to build a good relationship with the patient (Lloyd and Bor, 2004, p. 5).

Doctor-patient communication is a process in the organization where the doctor works. He/she guarantees the flow of information from its source to the user, i.e. the patient or family member (Bezenšek and Barle, 2007, pp. 175-176). Such a communication exceeds economic, social, cultural or interpersonal differences and produces trust, respect and co-operation. However, good communication does not necessarily mean that the doctor and the patient will agree in everything and it does not mean that there will be no dissatisfaction, mistakes, faults, complaints or even conflicts. These can also be the consequence of unrealistic expectations of the patients and their "blind trust" in medical technology as well as a lack of knowledge or understanding such procedures. Another reason could be the doctor's routine approach towards the patients, a lack of motivation for work or professional disinterest. This kind of complaints may be reduced by good communication.

Greene says that the majority of cultures do not use compulsive communication anymore, even "under-cover" compulsion, as he names it, is out and nowadays not used. The fact that it is not effective in motivation anymore is very important (Greene, 1991, p. 28).

When, in the process of communication, the doctor should get closer to the patient as a co-speaker and to show respect towards him/her. The doctor should try to listen to the patients and find out what they want, what troubles and motivates them. Ule (2003) accentuates that communication is based on mutual respect and she also exposes that communication is a form of treatment (as well). In each communication relationship there is an unfelt and priceless treatment potential hiding, however, there are unexpected dark sides which can arise as well and these arise due to the doctor's relationship towards him/herself or his/her own wounds which are hidden many times. Research has shown that being isolated from communication makes people sick. For such people seeing the doctor means running away from isolation and, of course, such patients wish to talk to the doctor even more. That is why the author emphasises that family doctors should "play" the role of a communication therapist (Ule, 2003, p. 131). If the patient sees that the doctor will not give any clear instruction and answers to his questions about his/her health problems, he feels helpless, numb and becomes inactive in the process of treatment. Their reactions are unmotivated and it seems that they accept their situation. That is why they do not ask questions nor express their doubt. They become "obedient", manageable, and especially in the process of treatment, they co-operate.

On the contrary, the patients' style of communication influences the doctor who should pay attention to the patient also on the level of his/her own perception of the disease. Research confirms that the patient's perception of the illness 
significantly influences the course of treatment. Surely, each doctor-patient relationship has its own characteristics. Unfortunately, patients do not have many positive communication experiences nowadays. From the doctor's point of view, the communication is mostly set into some conversational routine to find out the diagnosis and for further treatment. Research (Gottschlich, 1998, p. 10 cited in Ule, 2003) confirms that, due to this conversational routine, doctors do not obtain essential information which would be helpful for a higher quality treatment (Ule, 2003, pp. 131-132).

Some researchers (Fox, 1993, Hak, 1994, Roth, 1969, cited in Bezenšek and Barle, 2007, pp. 102) say that the way of communication between patients and doctors varies according to individual social groups. Based on their findings, communication is of a higher quality between the members from the middle and higher social classes, not due to the social status of the social groups nor their status in the community, but due to their similar cultural background since doctors originate from these social classes and therefore the cultural similarity is obvious.

Ule (cited in Janežič, 2004, pp. 22-23) accentuates that treatment has been connected with communication in different forms for ages. She exposes that communication is based on mutuality and mutual engagement of the doctor and the patient as in this way the dualism between the doctor and the patient is exceeded. However, here we have to consider that illness, as well as the process of treatment itself is not only the patient's problem but the doctor's as well. Ule is convinced that the doctor's words represent the means for helping and treating the patient, however they can also be harmful. This way the doctor and the patient become partners in the process of treatment. In this process communication plays a significant role as both the patient and the doctor act as partners in the process of communication complementing and assessing each other based on their experiences and knowledge. Often, we are not aware enough that conversation means a lot more to the patient than just medicine. Kind and friendly words let him/her hope to recover (Janežič, 2004, pp. 22-23). Unfortunately, communication is often a one-way process because patients (mostly) do not speak much or are silent, it is only the doctor who speaks. Kersnik (cited in Janežič, 2004, p. 23) believes that doctors should know and effectively use both the verbal and the non-verbal forms of communication. Most of all he/she should be able to lead a consultation with the patient, say bad news, ease the patient's and his/her relatives' acceptance of terminal phases, talk about mental signs without embarrassment, rationally use medicine for the treatment of mental problems and consult psychic help. The author reminds us that patients must feel that the doctor pays attention to them and is ready for consultation. However, such interaction requires the possession of communication skills (Janežič, 2004, pp. 23-24).

As our discussion includes the field of communication between the doctor and the patient, it is necessary to expose the fact which, by Ule (2003), is named 
motivating communication field. It is of elementary importance for a hurt modern human being. It is the communication between the doctor and the patient which has a main, central position, no matter if this position is opposed and underestimated in modern medicine. This is the reason why the relationship between the doctor and the patient is determined to fail in advance. The main problem here is the identity of both, what is the reason why doctors' communication is intended just for diagnosing, noticing and standardising the illness (Ule, 2003, p. 131).

\section{Patients' needs in communication with the doctor}

In the article Working toward the best doctor-patient communication (2011), Leo L. F., a psychiatrist and a representative of the Clinical Centre of the Pediatric Section in Singapore, presents the results of an analysis made in 1989. It revealed that doctor-patient communication is a one-way process as the doctor mainly gives instructions instead of allowing to run the communication mutually. Doctors should motivate patients to play an active role in the conversation, i.e. during the medical consultation including the discussion about a patient's physical condition. When patients notice that the doctor is listening to them, they starts to appreciate and consider them more. Such a process is very important for doctors as well since in mutual communication they can notice how the patient understands and accepts the whole medical process. If patients are involved in the process of communication in such a way, they can monitor and view their own treatment in a different way. The author accentuates that doctors are expected to explain the patients their health condition in a comprehensible way. He also consults an appropriate vocabulary that would allow and at the same time simplify and unify the process of doctor-patient communication. The same author exposes the function of the bio-psycho-social factor to assure a more qualitative communication with the patient. Doctors usually do not pay enough attention to the psycho-sociological views of treating the patient. The study by Baberg et al. (Baberg, 2001, cited in Leo, 2011, p. 721) notices that patients' problems are not only of medical but of psychologicalemotional nature as well. This is why the author emphasises that doctor-patient communication does not include only questions from the field of symptomatology but social, emotional and behavioural questions as well. In this way, both the doctor and the patient are more satisfied since the patient can cooperate actively in the process of treatment and thus help to establish a partnership with the doctor.

In order to make the doctor-patient communication effective, non-verbal communication is essential.

However, the non-verbal way of the doctor's communication is often disregarded. If non-verbal communication is suitable, indicators such as body language, eye contact and the colour of the voice indicate the patient the level 
and intensity of the doctor's interest in his health or health problem. At the same time, non-verbal communication can indicate how much and whether the doctor appreciates the information obtained from the patient. If a doctor manages and considers all the above mentioned, the patient is more satisfied. Surely, the doctor should be aware of the most important signs of non-verbal communication, e.g. face gestures, smiling, mimes, body language, hand position etc.

At this point, the author is right, claiming that a doctor should not use the mentioned elements in his/her communication, neither should he use them just as an example for the purpose of his communication with the patient. A successful, good quality communication process can be characterised by "the ability to communicate with patients in an ethical and effective way it has become a fundamental skill expected from each specialist." (Leo, 2011, pp. 720725)

Every interpersonal contact is mutual, which means that all we say or even do not express (through our appearance, movements, face expressions, dressing style, etc.) influences the other person. This person can react by showing appreciation, thoughts or even rejection. Our words and the facial expression can make one feel comfortable or, on the contrary, we can even cause some discomfort. When two people meet, their communication is always interactive. We sometimes feel uncomfortable because of the voice of the other person while communicating or even because the other person has no eye-contact with us. Despite all these facts, the conviction that communication is something usual, known to everybody and everyone knows how to communicate, prevails. Words are the essential means of conversation. Communication is always a process of awareness whereas silence expresses a dysfunction in communication. Especially in the field of sociology of health, there is lots of prejudice regarding communication, i.e. communication is unimportant due to other, more important activities and the patient is an unintellectual being who will not understand anything. However, appropriate communication can allow a faster and more correct diagnosis as well as more satisfaction of the patients (Rakovec-Felser, 2002, pp. 206-207).

A problem in doctor-patient communication is presented by the fact that doctors play several very important roles when organizing their work. These roles can be expressed in the process of communication. Thus, the doctor can function as "receptionist" who controls the flow of communication through a communication network. Such a position can be either formal or informal. $\mathrm{He} / \mathrm{she}$ can also have the function of a moderator or some bridge connecting individual communication sub-systems. It is important that the doctor as the transmitter of the information flow is among other team members, individuals and groups, however, he is not a part of sub-systems which connect them otherwise. A doctor can also be a leader of opinion, and as such plays an informal role of influencing opinions, values, behaviour and decisions of the 
patients. The doctor is a formal leader who is hidden. In this case, he/she must be confident, supportive and should have an influence on other group members (anonymous alcoholics). Here his/her role is to remove the limits within the organisation. The higher the doctor's position in the hierarchy of the organisation is, the stronger his influence on the flow of information is. Such a doctor has a lot of social power which is very important for his/her work as well as life environment (Bezenšek and Barle, 2007, p. 189).

When being in contact with patients, doctors are responsible both for the treatment of a particular illness or disease and patients as individuals. Gadžijev (cited in Janežič, 2004, p. 17) says that he/she is often told by young doctors that, during their studies, they were not taught how to communicate appropriately with patients and their family members.

A doctor must be aware of the fact that doctor/patient communication is a complex process, therefore he/she should be interested in the context of patient's life as well (family situation, work circumstances, status, relationships). $\mathrm{He} / \mathrm{she}$ should also learn about the patient's personal characteristics (self-image, social and cultural capacity, emotional strength, ability to control difficult situations, ability of self-defence, etc.). Furthermore, he/she has to learn about the history of the patient's disease, obtain sufficient information for setting the appropriate diagnosis and understand the patient's problems.

A bad doctor can be characterised as somebody who treats patients as numbers, and does not listen to them. Research has shown that not being treated as an individual with feelings and emotions, patients mostly perceive as unacceptable Thus, the lack of trust endangers the doctor-patient relationship. Patients are the ones who are forced to trust (Bezenšek and Barle, 2007, p. 103).

The actors of a communication process establish mutual connections, their own world and also try to keep these connections (Ule, 2009, p. 16).

The question of good communication with patients and of appropriate information delivery is of a great importance in medicine and health care. Philip Lay (cited in Payne and Walker, 2002, pp. 99-100) found that good communication is a very important component for patients. This is especially true when we want the patient to consider appropriately the doctor's advice regarding taking medicine, as inappropriate use of medicine can have bad consequences. The use of technical slang in medicine is a common communication problem as well.

Communication is a part of treatment, it is based on mutuality and mutual engagement, especially calming the other person. That is why effective communication in medicine depends on several factors. The most important factor here is to respect the patient and consider his/her views and opinions. During the process of communication, eye-contact is necessary and the doctor has to take his/her time to explain things in an appropriate, simple and comprehensible way (Prebil, Mohar and Fink, cited in Kapler, 2011, p. 31). 
Special features of communication, especially ethical principles, respecting the patient's personality, considering the obligation of secrecy, the patient's rights, his/her culture and the principle of co-operation which includes the principle of partnership without a hierarchy as well. Generally, it is necessary to get rid of the former relationship between a high-standing, all-knowing doctor and a totally dependent weak patient. Medical work should be based on interaction and it is the doctor who should take care of this. Thus, the relationship between the doctor and the patient should be warm, human and characterised by a certain level of sympathy on the side of the doctor. Certainly, the patient above all needs good treatment and not sympathy, but there is also some emotional affection needed which should not be an obstacle for a doctor (Trček, 1994, pp. 189-199).

Since the nature of doctor-patient communication is complex - it unites professional distance and the intimacy of the patient's problems, it is hard to set and define exact rules of communication. What is more, communication in this profession is influenced by various factors and, sometimes, by special, unusual situations. Nevertheless, there are some communication competencies that every doctor should possess, i.e.:

- $\quad$ giving exact and sufficient information,

- $\quad$ careful and active listening and reacting to the patient's resistance,

- correct or appropriate interpreting of the diagnosis, giving clear and comprehensible instructions to the patient, professional behaviour (especially when having a physical contact during health examination),

- $\quad$ respecting the patients' decisions and believes, obtaining credibility and trust.

There is no doubt that doctors must pay attention to each patient, treat them as subjects with own believes, fears, feelings and not as just one of several cases. Each patient is a different individual and, therefore, needs a different approach on the side of the doctor. The problem is that doctors do not have a universal recipe for successful communication and building a high quality relationship with their patients.

\section{Classification of doctor-patient relationships}

Židanik (cited in Janežič, 2004, p. 19) states that the doctor-patient relationship develops through three phases as follows:

- initial contact - i.e. defeating the first rejection up to the beginning of the therapeutic relationship - an active search for the doctor and making appointments with the recommended doctor,

- evaluation of the doctor - i.e. the phase of development or checking if the doctor is interested in the patient and the patient compares the doctor with other doctors and,

- the phase of balancing - i.e. the establishment of a mutual relationship - the doctor is adequate according to the patient's expectations. 
Here Ule notices that the relationship between the patient and the doctor is ambivalent, it is expanded from the patient's uncertainty to the doctor's routine. This is the point where several mistakes of communication between the doctor and the patient emerge from.

In medical practice, Wolf and Flis (Ule, cited in Janežič, 2004, p. 19) distinguish between three models of relationships between the doctor and the patient as follows:

- paternalistic model

- contractual model and

- partner model.

The paternalistic model is based on the doctor's ability and conviction that only he/she is able to help the patient with his/her health problem. In this model the patient is passive whereas the doctor is dominant. Simultaneously, this means that trust in the doctor-patient relationship is very important for treatment. The paternalistic relationship is mostly established when the patient's life is in danger, i.e. in case of accidents, epidemy, surgery, etc. In this model of cooperation the patient is passive and, therefore, totally depends on the doctor.

In the contractual model, the patient asks for medical service and meets a doctor who is the supplier of such medical service. This relationship is to be found in medical centres where various therapeutic and diagnostic services are offered (surgeries, sanatoriums, spas, rehabilitation centres, etc.). This model is more or less a part of marketing mechanism, which mainly occurs in labs, RTG, in cases of minor surgeries, in the field of aesthetic and plastic surgery.

Janežič (2004, pp. 19-20) believes that a partner relationship between the patient and the doctor is the one which allows the patient and the doctor to be equal partners in the process of treatment. Such a relationship is important especially in the treatment of chronic diseases. In this relationship the doctor is an experienced expert and the patient is his/her partner in the process of treatment. Such a relationship can also include the patient's family members who take part in the process of treatment. Ule (cited in Janežič, 2004, p. 20) notices that doctors often combine models of relationships, especially the contractual and the paternalistic relationship, since these do not require as much effort as the partner relationship does.

Gadžijev (cited in Janežič, 2004, p. 21) notices, that in communication with patients, doctors often try to hide their insufficient communication skills by presenting various papers and brochures including complications. Patients often welcome such an approach as they are given information about his disease. But it is not enough, doctors should pay more attention to their patients, they should be given a sufficient amount of information about their disease, diagnosis, treatment and possible complications.

Successful communication requires knowledge of the partner's culture on the doctor's side, i.e. the partner in the process of communication (e.g. the patient, family members, etc.). This mostly depends on the norms and values of the 
society in which the process of communication takes place. For instance, when meeting someone, a Slovene usually shakes hands whereas an Indian bows. If a doctor experiences major cultural differences at his work and in communication, he/she violates the rules and principles of the partner in case that he/she is not aware of them. This is not only uncomfortable but the doctor is also expected to expand his knowledge and to understand the messages in communication, i.e. be able to describe and foresee how the others will behave and to understand their reactions. The most frequent obstacles in communication between the doctor and foreigners are ethnocentrism, stereotypes and prejudice. Communication between people with the same or similar cultural background is definitely easier (Bezenšek and Barle, 2007, pp. 193-194).

Certain social and cultural factors come to expression when doctors meet people with other habits and from other cultural and social environment. In such cases, people behave in the way they were taught. Thus, communicating with foreign patients does not only mean understanding a foreign language but it also requires open-mindedness and a capacity to accept differentness. Belonging to a certain social class influences the way how somebody accepts, understands and reacts in a certain situation. Thus, the factors of our environment are connected not only to social but also to cultural factors. The technical aspects of communication are important as well, especially nowadays. As much information as possible must be processed in a short time. Media and IT-systems play a crucial role here. The latter have a great influence on the possibility of diagnosing and clinical treatment and they are more and more included in the work of nurses and doctors (Filipič, 1998, pp. 221-222).

In the report by the Association of American Medical Colleges entitled Contemporary Issues in Medicine: Communication in Medicine (Report III), in the chapter discussing the importance of effective communication in medicine one can find a research by Barbara Korsch et al., published in the late 1960s, which inspired several studies about communication between doctors and patients. The resolution, confirmed by two committees, i.e. the Liaison Committee on Medical Education and the Committee of the Accreditation of Canadian Medical Schools in 1995, confirms this need for more and more knowledge in the field of communication in medicine in North America. Communication skills are essential for the effectiveness of doctors' work. Their skills have to be assessed and developed by instruction. They refer to their responsibilities including communication with patients, the patients' families, colleagues and other medical staff. Similar orders from the past, obviously were not sufficient in order to change the curriculum. Theory and practice of developing communication skills need systematic attention, elementary knowledge of communication has to be included in the medical curriculum and communication skills have to be assessed. The development and extension of a humanistic approach, which is focused on the patient, have to be accented (Association of American Medical Colleges, 1999, pp. 5-6). 


\section{Conclusion}

The analysis presented allows us to conclude that the global problem of communication in medicine or the doctor-patient communication is in the centre of attention of medicine and health care. Thus, personal, sincere communication between the doctor and the patient on an interpersonal level is an important process stretching to the field of science and social values as well.

Research shows that there is still a lot to do in order to improve the relationship between the patient and the doctor in the field of communication. A survey among the Slovene public (Toš and Malnar, 2002, cited in Bezenšek and Barle, 2007, pp. 125-126) confirmed a high level of trust in doctors as two thirds of the respondents stated that their doctor does everything for them. According to the interviewees, the profession of the doctor enjoys a high level of reputation as well. Furthermore, it is necessary to accentuate the fact that the results showed great correlation between the feelings of happiness and the health of people. The contentment of people referring to their life and feelings of happiness is much worse when their health condition is bad (Bezenšek and Barle, 2007, p. 126).

It is a fact that there is a shift as for healthy lifestyle. Programs supporting better health of individuals gain more and more attention. Thus, expectations regarding the doctor-patient relationship are high. This means that the paternalistic or the contractual model of relationship should grow into the partner model or cooperation between the doctor and the patient which would guarantee an increased quality of values in the society.

\section{References}

Associaton of American Medical Colleges. Contemporary Issues in Medicine: Communicaton in Medicine. Report III, 1999, 1-29.

BACH, S. and GRANT, A. Communication and interpersonal skills for nurses. Southernhay East: Learning Matters, 2009.

BALAŽIC, J. and KORNHAUSER, P. Medicinska etika: deontološka vprašanja pri delu zdravnika. Ljubljana: Medicinska fakulteta, Inštitut za sodno medicine, 2003.

BEZENŠEK, J. and BARLE, A. Poglavja iz sociologije medicine. Maribor: Medicinska fakulteta, 2007.

BRAJŠA, P. Človek, spolnost, zakon. Ljubljana: Delavska enotnost, 1982.

FILIPIČ, I. (1998): Komunikacija v zdravstveni negi. Obzornik zdravstvene nege, 1998, 32, 221-225.

GOTTSCHLICH, M. Sprachloses Leid: Wege zu einer kommunikativen Medizin: die heilsame Kraft des Wortes. Wien: New York: Springer, 1998.

GREENE, H. R. Nov način komunikacije: praktični nasveti za boljše poslovno in družinsko sporazumevanje. Ljubljana: Samozaložba, 1991. 
JANEŽIČ, M. Komunikacija med bolniki v informacijski družbi. Diploma thesis. Ljubljana: Fakulteta za družbene vede, 2004.

KAPLER, T. Komunikacija v zdravstvu. Zaključna projektna naloga. Koper: Fakulteta za management, 2011.

NEO, L. F. (2011): Working towards the best doctor - patient communication. Rewiew Article. Singapore Med J, 2011, 52(10), 720-725.

LLOYD, M. and BOR, R. Communication skills for Medicine 2e., Philadelphia: Elsevier's Health Science Rights Department in Philadelphia, 2004.

PAYNE, S. and WALKER, J. Psihologija v zdravstveni negi. Ljubljana: Educy, 2002.

RADLEY, A. Making Sense of Illness. Sage, London, 1995.

RAKOVEC- FELSER, Z. Zdravstvena psihologija. Maribor: Visoka zdravstvena šola, 2002.

TRČEK, J. Medosebno komuniciranje in kontaktna kultura. Radovljica: Didakta, 1994.

ULE, M. Psihologija komuniciranja in medosebnih odnosov. Ljubljana: Fakulteta za družbene vede, 2009.

http://www.zdravniskazbornica.si/zzs.asp?FolderId=386

http://www.zdravniskazbornica.si/zzs.asp?FolderId=386 (6.11.2010)

http://med.over.net/forum5/read.php?358,6396482,6398632 (12.11.2010)

http://med.over.net/forum5/read.php?13,537007.. (12.11.2010)

http://www.dpbs.si/upload/63577491ee_KAKO_DOBRO_KOMUNICIRATI_Z

_ZDRAVNIKOM.pdf 